Gut, 1977, 18, 670-672

\title{
Carbohydrate content of endoscopic gastric biopsies in carcinoma of the stomach
}

\author{
G. MACHADO, J. R. CLAMP, AND A. E. READ \\ From the Department of Medicine, Bristol Royal Infirmary, Bristol
}

SUMMARY An investigation of the glycoproteins of gastric mucus from biopsies of patients with gastric cancer has shown a change in certain carbohydrate components. There is a significant increase $(\mathrm{P}<0.001)$ in mannose and a significant decrease in $N$-acetylgalactosamine in both secretors and non-secretors from cancer-free and cancer-bearing regions of the stomach as compared with normal stomachs. The possible reasons for this change and its relation to two possible glycoprotein fractions are discussed.

Endoscopic gastric biopsies are mainly composed of the superficial layer of the stomach because of the limited size of the forceps. Histochemical studies conducted by Doberneck and Engle (1966) showed that mucus is the major carbohydrate-containing component of this layer. Barton et al. (1972) and Brown et al. (1972) have demonstrated that the carbohydrate composition of these biopsies is almost exclusively contributed by mucous glycoproteins within cells or adherent to the epithelial surface. Gastric biopsies were, therefore, used as a convenient screening procedure in order to investigate, firstly, the mucous glycoproteins from normal individuals and from patients with carcinoma of the stomach, and, secondly, the mucous glycoproteins from cancerbearing and cancer-free areas of the same diseased stomachs.

\section{Methods}

All patients studied were referred to the Digestive Endoscopy Unit, University Department of Medicine, Bristol Royal Infirmary.

Endoscopic examinations were performed and gastric biopsies were taken from 37 subjects in whom barium meal and upper gastrointestinal endoscopy were normal, and from 27 patients with carcinoma of the stomach.

In patients with gastric carcinoma, biopsies were taken from the tumour (cancer-bearing area) and from an area free of tumour (cancer-free area). As far as possible, biopsies were taken from each area in

Received for publication 9 February 1977 duplicate. One specimen was placed in $10 \%$ formolsaline solution for histopathology. The paraffin embedded biopsy tissue was treated as described elsewhere (Machado et al., 1975) and the final diagnosis was made by histopathological examination. The second specimen was placed in absolute ethanol for 24 hours at $4^{\circ} \mathrm{C}$, then transferred to a previously weighed $2 \mathrm{ml}$ ampoule and dried in a vacuum desiccator to constant weight. The internal standards mannitol and perseitol were added according to the dry weight of the samples, so that approximately $0 \cdot 1$ $\mu \mathrm{mol}$ was added for each milligram of sample.

The ampoules were dried once more and stored in a desiccator until ready for analysis.

The method described by Clamp (1974) was used for the analysis of the following monosaccharides, L-fucose (Fuc); D-mannose (Man); D-galactose (Gal); $N$-acetylglucosamine (GlcNAc); $N$-acetylgalactosamine (GalNAc); $N$-acetylneuraminic acid (sialic acid; SA).

Blood-group activity (A, B, and $\mathrm{H}$ ) of all patients was determined using methods based on those of Boormann and Dodd (1970).

\section{Results}

Of the 37 normal individuals 12 were non-secretors, whereas the 27 patients with carcinoma of the stomach contained 15 non-secretors. This difference has been noted previously (Doll et al., 1961).

The monosaccharide contents of the mucous glycoproteins in the biopsies were analysed and the results were examined according to the blood-group activity and secretor status of each individual. 
Table 1 Carbohydrate content of gastric biopsies from individuals who were secretors of $A B H$ blood-group substances

\begin{tabular}{|c|c|c|c|c|c|c|}
\hline & $\begin{array}{l}\text { Fuc } \\
\text { Mean (SD) }\end{array}$ & $\begin{array}{l}\text { Man } \\
\text { Mean }(S D)\end{array}$ & Gal & $\begin{array}{l}\text { GlcNAc } \\
\operatorname{Mean}(S D)\end{array}$ & $\begin{array}{l}\text { GalNAc } \\
\text { Mean }(S D)\end{array}$ & $\begin{array}{l}\text { NeuNAc } \\
\text { Mean }(S D)\end{array}$ \\
\hline $\begin{array}{l}\text { I. Normal group } \\
(\mathrm{n}=25) \\
\text { II. Carcinoma group } \\
(\mathrm{n}=12)\end{array}$ & $4.1(0.8)$ & $1.0(0.2)$ & 6.0 & $4.6(0.4)$ & $4.0(0.8)$ & $0.5(0.2)$ \\
\hline 1. Cancer-bearing area & $\begin{array}{l}3.7(0.4) \\
\text { NS } \\
3.8(0.4) \\
\text { NS }\end{array}$ & $\begin{array}{l}1.7(0.4) \\
P<0.001 \\
1.5(0.4) \\
P<0.001\end{array}$ & $\begin{array}{l}6.0 \\
6 \cdot 0\end{array}$ & $\begin{array}{l}4.8(0.2) \\
\text { NS } \\
4.8(0.5) \\
\text { NS }\end{array}$ & $\begin{array}{l}2.6(0.3) \\
P<0.001 \\
2.8(0.4) \\
P<0.001\end{array}$ & $\begin{array}{l}0.6(0.3) \\
\text { NS } \\
0.4(0.2) \\
\text { NS }\end{array}$ \\
\hline
\end{tabular}

The results are given as mean (standard deviation) and are expressed as residues of monosaccharide relative to a galactose content of 6.0 residues. A comparison between normal subjects and those with carcinoma of the stomach with their significance (P value) is also given. Abbreviations are as follows: Fuc, fucose; Man, mannose; Gal, galactose; GlcNAc, $N$-acetylgucosamine; GalNAc, $N$-acetylgalactosamine; NeuNAc, $N$ acetylneuraminic acid; $n$, number of patients; NS, not significant.

Table 2 Carbohydrate content of gastric biopsies from individuals who were non-secretors of ABH blood-group substances

\begin{tabular}{|c|c|c|c|c|c|c|}
\hline & $\begin{array}{l}\text { Fuc } \\
\text { Mean }(S D)\end{array}$ & $\begin{array}{l}\text { Man } \\
\text { Mean }(S D)\end{array}$ & Gal & $\begin{array}{l}\text { GlcNAc } \\
\operatorname{Mean}(S D)\end{array}$ & $\begin{array}{l}\text { GalNAc } \\
\text { Mean }(S D)\end{array}$ & $\begin{array}{l}\text { NeuNAc } \\
\text { Mean }(S D)\end{array}$ \\
\hline $\begin{array}{l}\text { I. Normal group } \\
(n=12) \\
\text { II. Carcinoma group } \\
(n=15)\end{array}$ & $1.2(0.3)$ & $1.3(0.4)$ & $6 \cdot 0$ & $4.3(0.3)$ & $3.8(0.7)$ & $0.4(0.1)$ \\
\hline $\begin{array}{l}\text { 1. Cancer-bearing area } \\
\text { 2. Cancer-free area }\end{array}$ & $\begin{array}{l}1.6(0.3) \\
\text { NS } \\
1.6(0.2) \\
\text { NS }\end{array}$ & $\begin{array}{l}2.2(0.5) \\
P<0.001 \\
2.0(0.2) \\
P<0.001\end{array}$ & $\begin{array}{l}6.0 \\
6.0\end{array}$ & $\begin{array}{l}4.6(0.5) \\
\text { NS } \\
4.5(1 \cdot 2) \\
\text { NS }\end{array}$ & $\begin{array}{l}2.2(0.4) \\
P<0.001 \\
2.6(0.3) \\
P<0.001\end{array}$ & $\begin{array}{l}1.4(0.5) \\
P<0.001 \\
0.8(0.5) \\
\text { NS }\end{array}$ \\
\hline
\end{tabular}

The results are given as mean (standard deviation) and are expressed as residues of monosaccharide relative to a galactose content of 6.0 residues. A comparison between normal subjects and those with carcinoma of the stomach with their significance (P value) is also given. Abbreviations are as in Table 1.

Tables 1 and 2 show that there are statistically significant $(\mathrm{P}<0.001)$ differences between normal and carcinomatous stomachs in both secretors and non-secretors. The significant changes are an increase in mannose and a reduction in $N$-acetylgalactosamine. There is also a significant increase in $N$ acetylneuraminic acid in the tumour area of cancerous stomachs of non-secretors. However, this change is not seen elsewhere and, as the glycosidic linkage of this monosaccharide is very labile, the significance of such differences is difficult to assess.

In both secretors and non-secretors, the changes in mannose and $\mathrm{N}$-acetylgalactosamine are found in the cancerous tissue as well as in the non-malignant parts of the stomach. It was not found possible to quantitate satisfactorily the degree of gastritis found in the biopsies from the cancer-free areas. Chronic gastritis was, however, found to some degree in all specimens.

\section{Discussion}

There are a number of advantages in using biopsy material for monitoring changes in mucous glyco- proteins. Thus, the material collected is less contaminated by other secretions such as saliva or bile, the mucous glycoproteins are less likely to have been degraded by enzymes than those present in aspirated gastric juice, and finally the analyses can be carried out on material from defined areas of the stomach.

Gas-liquid chromatography was the method used for the determination of the monosaccharide content of glycoproteins throughout this study. This technique can handle, in a single procedure, all the monosaccharides likely to be present in mucous glycoproteins and related materials, or in possible contaminants. These monosaccharides include ribose, xylose, fucose, mannose, galactose, glucose, $\mathrm{N}$ acetylglucosamine, $N$-acetylgalactosamine, sialic and glucuronic acids, as well as fatty acids and a number of other substances.

When comparing the carbohydrate content of mucous glycoproteins from different individuals it is important to assess the results in relation to secretor status because of the changes in monosaccharide content-for example, fucose-associated with this (Clarke et al., 1959; Doll et al., 1961; Schrager and 
Oates, 1973). In order to make comparisons between the various groups easier to assess, the results are given as molar proportions relative to a content of six residues of galactose.

The fact that two significant changes in monosaccharide content are seen in patients with gastric cancer is of interest. Fraser and Clamp have shown (1975) that the proportions of these two sugars often vary inversely with evidence for two possible types of glycoprotein present in mucus, one low in mannose and high in $N$-acetylgalactosamine, while the other has a higher content of mannose and a lower content of $\mathrm{N}$-acetylgalactosamine. These two glycoprotein fractions may arise from different types of cell. The fact that both the cancerous and non-cancerous areas of cancer-bearing stomachs show carbohydrate changes suggests a change in the relative amounts of these two fractions and therefore a corresponding change in the cells giving rise to them. This might be explained for the non-cancerous areas by the presence of chronic gastritis-an almost universal precancerous feature (Morson, 1955; Laurén, 1965; Morson and Dawson, 1972). In the cancerous parts where similar changes are found, it might also signify the effects of epithelial hypersecretion of glycoprotein because of a tumour origin from this gastritic mucosa or it could simply represent the effects of a decreased production by the goblet cells. The former explanation is more likely, as Häkkinen et al. (1968) have detected a sulphoglycoprotein antigen in gastric carcinoma and found that this antigen was also present in mucosal areas not involved by tumour. The sulphoglycoprotein often had blood group activity that differed from the patient's red blood cells and similar anomalous blood group activity has been found in gastric carcinoma secretions by Häkkinen and Virtanen (1967) and Schrager and Oates (1973).

Changes in blood group activity are associated with changes in the terminal monosaccharide residues of oligosaccharide units of mucous glycoproteins. Changes in monosaccharide content have been found directly by analyses of secretions from gastric carcinoma. Richmond et al. (1955) found significant differences in total hexose, fucose, and sialic acid and Schrager and Oates (1973) showed variations between the proportions of galactose, $N$ acetylglucasime and $N$-acetylgalactosamine. These results were obtained with gastric secretions and our results with biopsies confirm these findings. In addition, the ability to carry out carbohydrate analyses on precise areas of stomach has provided biochemical support for the histological findings of Häkkinen et al. (1968) that there are glycoprotein changes in apparently normal areas of cancer-bearing stomachs.

These changes could perhaps be of diagnostic help, as, with refinement in techniques, isolation and carbohydrate analysis of adherent gastric mucus could, by indicating areas of altered carbohydrate content, possibly indicate a susceptibility to cancer even before histological change has occurred.

\section{References}

Barton, W., Brown, P., and Clamp, J. R. (1972). The carbohydrate content of mucosal biopsies. Clinica Chimica Acta, 36, 262-263.

Boorman, K. E., and Dodd, B. (1970). An Introduction to Blood-Group Serology, 4th edn. Churchill: London.

Brown, P., Clamp, J. R., and Salmon, P. R. (1972). The carbohydrate containing component of gastric mucosal biopsies. (Abstract.) Gut, 13, 1026.

Clamp, J. R. (1974). Analysis of glycoproteins. Biochemical Society Symposia, 40, 3-16.

Clarke, C. A., Evans, D. A. P., McConnell, R. B., and Sheppard, P. M. (1959). Secretion of blood group antigens and peptic ulcer. British Medical Journal, 1, 603-607.

Doberneck, R. C., and Engle, J. C. (1966). Quantitative evaluation of the gastric mucosa of normal subjects and subjects with various gastric disorders. Surgery, 59, 189 194.

Doll, R., Drane, H., and Newell, A. C. (1961). Secretion of blood group substances in duodenal, gastric and stomal ulcer, gastric carcinoma and diabetes mellitus. Gut, 2, 352359.

Fraser, D., and Clamp, J. R. (1975). The glycoprotein content of meconium. Clinica Chimica Acta, 59, 301-307.

Häkkinen, I., Järvi, O., and Grönroos, J. (1968). Sulphoglycoprotein antigens in the human alimentary canal and gastric cancer. An immunohistological study. International Journal of Cancer, 3, 572-581.

Hăkkinen, I. P. T., and Virtanen, S. (1967). The blood group activity of human gastric sulphoglycoproteins in patients with gastric cancer and normal controls. Clinical and Experimental Immunology, 2, 669-675.

Laurén, P. (1965). The two histological main types of gastric carcinoma: diffuse and so-called intestinal-type carcinoma. An attempt at a histoclinical classification. Acta Pathologica et Microbiologica Scandinavica, 64, 31-49.

Machado, G., Rubens, J., Brown, P., and Davies, J. D. (1975). Evaluation of biopsy in the diagnosis of early gastric cancer. Aktuelle Gastrologie, 4, 65-67.

Morson, B. C. (1955). Carcinoma arising from areas of intestinal metaplasia in the gastric mucosa. British Journal of Cancer, 9, 377-385.

Morson, B. C., and Dawson, I. M. P. (1972). Gastrointestinal Pathology. Blackwell: London.

Richmond, V., Caputto, R., and Wolf, S. (1955). Biochemical study of the large molecular constituents of gastric juice. Gastroenterology, 29, 1017-1021.

Schrager, J., and Oates, M. D. G. (1973). A comparative study of the major glycoprotein isolated from normal and neoplastic gastric mucosa. Gut, 14, 324-329. 